\title{
Alexithymia and drug addiction: is there a missing link?
}

\begin{abstract}
Alexithymia is a personality construct characterized by the inability to identify and describe emotions. The core characteristics of alexithymia are a marked dysfunction in emotional awareness, social attachment, and interpersonal relating. Furthermore, alexithymics have difficulty in distinguishing and appreciating the emotions of others, which is thought to lead to unempathic and ineffective emotional responding. Alexithymia is prevalent in approximately $10 \%$ of the general population and is known to be comorbid with a number of psychiatric conditions. Research shows that it is common among individuals with substance use disorders, suggesting that is a trait that may contribute to substance dependence. This paper will review alexithymia as it relates to substance use and substance use disorders, considering its potential role in the maintenance and treatment of these disorders.
\end{abstract}

Volume 3 Issue 3 - 2017

\author{
Ricardo João Teixeira ${ }^{1,2}$ \\ 'Department of Education and Psychology, University of Aveiro, \\ Portugal \\ 2Psychology Department Coordinator at Clínica da Ordem, \\ Portugal
}

\begin{abstract}
Correspondence: Ricardo João Teixeira, Psychology Department Coordinator at Clínica da Ordem, Porto, Portugal, Tel 351917837323, Email ricardojft@gmail.com
\end{abstract}

Received: April 14, 2017 | Published: April 20, 2017

Keywords: alexithymia, addictions, connections

\section{Introduction}

Although initially alexithymia has been associated with psychosomatic disorders, alexithymic features can be found in other groups of patients. Neuroses of character, drug addiction, sexual perversions, patients with major affective disorder, post-traumatic disorders, psychopaths or antisocial personalities, patients with eating disorders, alcoholism and other forms of abuse and dependence of psychoactive substances, and narcissistic personality disorder. ${ }^{1-6}$ That is, frameworks in which access to the psychic elaboration of conflicts and internal tensions seems to be compromised. Alexithymia is a multidimensional concept associating an emotional component focused on the difficulty in identifying and describing feelings and a cognitive one centered on the use of a concrete and poorly introspective way of thinking.

Particularly in drug addicts, the alexithymic characteristics manifest themselves through a chronic inhibition of the self, which is turned to itself, only related to the environment through drugs. ${ }^{7}$ Inappropriate to verbalize appropriate affections, drug addicts tend to be hypochondriacally concerned with the sensations of the body that accompany the awakening of emotions and with an imperative need to block themselves by ingesting psychoactive substances. ${ }^{8}$ $\mathrm{Krystal}^{9}$ concluded that without a cognitive aspect of emotion, such as the expressive component and the capacity for self-reflection, drug-dependent subjects are unable to recognize that they are gaining experiences through feelings just as they are incapable of to identify them. Taylor et al. ${ }^{10}$ admit that depressive suffering may contribute to a component of state-dependent alexithymia, but understands that the results around high rates of alexithymia, among drug-dependent individuals, in a stable phase of rehabilitation programs and with prolonged abstinence periods, strongly suggest the simultaneous existence of a structural trait. As $\mathrm{Krystal}^{9}$ explains, psychoactive substances are used with a pharmacological meaning, to manipulate affective states of individuals, and as an instrument to temporarily acquire self-esteem and self-regard. According to Wurmser, ${ }^{11}$ individuals prone to substance dependence seem to give up the ability to experience their affective world, both intrinsically and extrinsically.
Based on the Toronto Alexithymia Scale (TAS and TAS-20), several authors found significant rates of alexithymia among drug addicts: $50.4 \%$ in a sample of mixed substance abusers, ${ }^{12} 50 \%$ in a group of recently abstinent drug abusers, ${ }^{13} 66 \%$ in a group of 87 heroin addicts who were abstinent 22 months ago; ${ }^{14} 42 \%$ in a sample of 204 substance-dependent patients who completed the TAS during their first week of hospitalization, ${ }^{15} 48 \%$ in a sample of 60 alcoholics, whose mean abstinence time was 22 months (interestingly, participants with less abstinence time showed higher levels of alexithymia); ${ }^{16} 81 \%$ in a sample of 32 young drug addicts (with an average of 6 years of heroin and / or cocaine use) ${ }^{7}$ in an expressive sample of 2297 middle-aged men, Kauhanen et al ${ }^{17}$ found a close association between alexithymia and alcohol consumption.

More recent studies report that rates of alexithymia in the general population are estimated to range between 6 and $10 \%,{ }^{18,19}$ but alexithymia is more frequently observed in individuals with substanceuse disorders. As many as $78 \%$ of individuals with alcohol-use disorders have been reported to have some level of alexithymia, ${ }^{20}$ with percentages typically in the range of 45 to $67 \% .{ }^{21}$ Alexithymia has also been associated with a family history of alcoholism. ${ }^{22}$ Individuals with illicit drug use disorders also frequently exhibit alexithymia, with $42 \%$ in one study and $50 \%$ in another meeting the criteria for alexithymia. ${ }^{15}$ When compared to non-addicted individuals, those with substance-use disorders more frequently exhibit alexithymia. ${ }^{23}$ Alexithymia is also frequently seen in participants who are undergoing drug abuse treatment, ${ }^{24}$ and research has suggested that alexithymia itself may be a difficult characteristic to change.

Although there are longitudinal studies exploring the relationships among alexithymia, drug addiction and associated psychopathology, they have been going on for quite limited periods of time: ${ }^{12} 3$ weeks: ${ }^{25}$ 4-6 weeks: ${ }^{26} 12$ weeks. The time factor is fundamental, because there are difficulties to diagnose the disturbance, as well as a prolonged evolution of most of the treatment processes. In the samples from the three studies cited, the scores obtained on the TAS-20 remained stable over the referred periods. Thus, it is important to note that despite the short duration of these prospective studies, the results support the view that alexithymia is not merely a secondary phenomenon to 
depression or withdrawal. ${ }^{10}$ Based on studies with addicted subjects, some authors ${ }^{27,28}$ concluded that it might be necessary to investigate the deficits in self-regulation in drug addicts' samples. The authors point out that addicts become dependent on psychoactive substances because of their enormous difficulties in modulating, regulating and expressing affections.

In summary, the view that many patients with imbalances caused by psychoactive substances develop alexithymia, as a result of severe anxiety and depression, has been strongly argued. ${ }^{12}$ This line of approach to alexithymia seems to support that, in individuals dependent on psychoactive substances, this disturbance is a situational response to emotions. It can be inferred that, since alexithymia is a characteristic of many drug addicts, drugs and alcohol can act as an 'antidote' for alexithymia, since on its effects, the patient is able to express feelings and emotions, which without it, could never convey. ${ }^{29}$ Finally, in this line of thinking, Fernandez et al. ${ }^{30}$ concluded that alexithymia seems to be significantly related to variables of consumption history, drug dependence, self-concept, interpersonal anxiety and assertiveness, self-efficacy in risk situations for the consumption of heroin, perception of social environment and some human values. ${ }^{30}$ The relationship between alexithymic traits and drug dependence remains quite unclear, mainly due to the lack of longitudinal studies. However, is seems plausible to assert that alexithymia may interfere with treatment success, as patients for whom it is difficult to recognize and describe emotional states may not be able to adequately regulate these states or recognize their relationship to initiation or maintenance of drug use. ${ }^{31}$

\section{Acknowledgements}

None.

\section{Conflict of interest}

The author declares no conflict of interest.

\section{References}

1. Lesser IM. A review of the alexithymia concept. Psychosom Med. 1981;43(6):531-543

2. Lolas F, Von Rad M. Alexithymia. Psychosomatic Medicine Theory, Physiology and Practice. 1989;1:189-237.

3. Lumley MA, Roby KJ. Alexithymia and pathological gambling. Psychother Psychosom. 1995;63(3-4):201-206.

4. Salminen JK, Saarijärvi S, Aärelä E. Two decades of alexitimia. $J$ Psychosom Res. 1995;39(7):803-807.

5. Taylor GJ. Alexithymia: concept, measurement, and implications of treatment. Am J Psychiatry. 1984;141(6):725-732.

6. Taylor GJ. The alexithymia construct: conceptualization, validation, and relationship with basic dimensions of personality. New Trends in Experimental \& Clinic Psychiatry. 1994;10(2):61-74.

7. Joaquim Gago, Domingos Neto. Alexitimia e Toxicodependência. Revista Toxicodependência. 2001;7(3):19-22.

8. Cristina Fabião. Toxicodependência: Duplo Diagnóstico, Alexitimia e Comportamento: Uma Revisão. Revista Toxicodependência. 2002;8(2):37-51.

9. Krystal H. Integration and self-healing. Affect-trauma-alexithymia. USA: The Analytic Press, Hillsdale; 1988.
10. Taylor GJ, Bagby RM, Parker JD. Disorders of affect regulation: alexitimia in medical and psychiatric illness. New York: Cambridge University press; 1997.

11. Wurmser L. Flight from conscience: Experiences with the psychoanalytic treatment of compulsive drug abusers. J Subst Abuse Treat. 1987;4(34):157-168.

12. Haviland MG, Shaw D, Mac Murray JP. Alexithymia: subscales and relationship to depression. Psychother Psychosom. 1988;50(3):164-170.

13. Taylor GJ, Bagby RM, Parker JD. A preliminary investigation o alexithymia in men with psychoactive substance dependence. Am J Psychiatry. 1990;147(9):1228-1230.

14. Delle Chiaie R, Cianconi P, Didonna A, et al. Alexithymia in opioid addicts. State dependent reaction or permanent trait? Presented at the 20th European Conference on Psychosomatic Research, Gent, Belgium; 1994.

15. Haviland MG, Hendryx MS, Shaw DG, et al. Alexithymia in women and men hospitalized for psychoactive substance dependence. Compr Psychiatry. 1994;35(2):124-128.

16. Ziolkowski M, Gruss T, Rybakowski JK. Does alexithymia in male alcoholics constitute a negative factor for maintaining abstinence? Psychother Psychosom. 1995;63(3-4):169-173.

17. Kauhanen J, Kaplan GA, Cohen RD, et al. Alexithymia and risk of death in middle-aged men. J Psychosom Res. 1996;41(6):541-549.

18. Kokkonen P, Karvonen JT, Veijola J, et al. Prevalence and sociodemographic correlates of alexithymia in a population sample of young adults. Compr Psychiatry. 2001;42(6):471-476.

19. Hintikka J, Honkalampi K, Lehtonen J, et al. Are alexithymia and depression distinct or overlapping constructs? A study in a general population. Compr Psychiatry. 2001;42(3):234-239.

20. Rybakowski J, Ziółkowski M, Zasadzka T, et al. High prevalence of alexithymia in male patients with alcohol dependence. Drug Alcohol Depend. 1988;21(2):133-136.

21. Thorberg FA, Young RM, Sullivan KA, et al. Alexithymia and alcohol use disorders: A critical review. Addict Behav. 2009;34(3):237-245.

22. Pombo S, Costa NF, Ismail F, et al. Alexithymia and alcohol dependence: do different subtypes manifest different emotion regulations? Addiction Research \& Theory. 2015;23(3):187-195.

23. Ghalehban M, Besharat MA. Examination and comparison of alexithymia and self-regulation in patients with substance abuse disorder and normal individuals. Procedia-Social and Behavioural Sciences. 2011;30:38-42.

24. Lyvers M, Hinton R, Gotsis S, et al. Traits linked to executive and reward systems functioning in clients undergoing residential treatment for substance dependence. Personality and Individual Differences. 2014;70:194-199.

25. Pinard L, Negrete JC, Annable L, et al. Alexithymia in substance abusers-persistence and correlates of variance. The American Journal on Addictions. 1996;5(1):32-39.

26. Keller DS, Carroll KM, Nich C, et al. Alexithymia in cocaine abusers response to psychotherapy and pharmacotherapy. The American Journal on Addictions. 1995;4(3):234-244.

27. Khantzian EJ. Self-regulation and self-medication factors in alcoholism and the addictions. Similarities and differences. Recent Dev Alcohol. 1990;8:255-271.

28. Carolyn M Bell, Edward J Khantzian. Contemporary psychodynamic perspectives and the disease concept of addiction: Complementary or competing models? Psychiatric Annals. 1991;21(5):273-281. 
29. Taylor GJ. Recent development in alexithymia theory and research. Can J Psychiatry. 2000;45(2):134-142.

30. Fernandez Gomez C, Espina Eizaguirre A, Aresti A. Alexitimia y características clínicas en abuso de opiáceos. Revista Toxicodependências. $1997 ; 3: 77-85$
31. Morie KP, Yip SW, Nich C, et al. Alexithymia and Addiction: A Review and Preliminary Data Suggesting Neurobiological Links to Reward/Loss Processing. Curr Addict Rep. 2016;3(2):239-248. 